\title{
EVAluation of Fluoroscopically Guided CAUdal EPIDURAL INJECTIONS
}

Laxmaiah Manchikanti, MD, Kim A. Cash, RT, Vidyasagar Pampati, MSc, Carla D. McManus, RN, BSN, and

Kim S. Damron, RN

Objective: To evaluate accuracy of needle placement and flow patterns of fluoroscopically guided caudal epidural injections.

Design: A prospective observational study of patients with low back pain undergoing caudal epidural injections under fluoroscopy.

Background: Epidural administration of corticosteroids is one of the commonly used interventions in managing chronic low back pain. Sacral or caudal epidural placement of the needle is one of the commonly used means to access the lumbar epidural space for administration of various drugs.

Methods: A total of 100 consecutive patients underwent fluoroscopically guided caudal epidural injections. Needle insertion was performed blindly (without the use

Access to the epidural space through sacral hiatus is one of the most commonly utilized techniques in managing chronic low back pain with epidural injection of local anesthetic or steroid, percutaneous adhesiolysis, or spinal endoscopic adhesiolysis. Caudal epidural injection technique enjoyed significant popularity over the years since the first reports of its use in low back pain (1-3) due to the ease of the technique and safety (4-7). Reports of the effectiveness of epidural corticosteroids have varied from $18 \%$ to $90 \%$ (8). However, evaluation of the effectiveness of caudal epidural steroid injections separate from transforaminal and interlaminar injections have shown that caudal epidural steroids overall are superior to interlaminar epidural injections and almost similar to transforaminal epidural in-

From Pain Management Center of Paducah, Paducah, KY. Address Correspondence: Laxmaiah Manchikanti, MD, 2831 Lone Oak Road, Paducah, KY-42003.

E-mail: drm@apex.net

Funding: There was no funding provided by any commercial entity in preparation of this manuscript.

Conflict of Interest: None of fluoroscopic guidance) based on palpable landmarks, palpation of subcutaneous airflow, subjective impression that the needle was in a satisfactory position, and ease of injection of contrast. These clinical criteria were compared with the position of the needle as seen under fluoroscopy and the spread of radiopaque contrast in the epidural space. The contrast flow patterns, ventral or dorsal epidural filling, nerve root filling, and correlation of filling to the side of pain were evaluated.

Results: Successful injection placement without fluoroscopic visualization was confirmed on subsequent fluoroscopic visualization in $77 \%$ of the patients. Various filling and flow patterns showed that with injection of $10 \mathrm{~mL}$ of contrast, filling was noted up

jections with added safety (5-18).

A common problem encountered with any epidural injection, is inaccurate needle placement, which also results in inaccurate placement of the injectate (19). Thus, several authors have recommended that all epidural injections be performed using fluoroscopic guidance. It is touted that this practice not only would improve the accuracy of needle placement, but would decrease the risk of a subarachnoid puncture, decrease intrathecal or intravascular injection, and facilitate accurate delivery of injectate, in turn improving the outcomes. Multiple authors have evaluated accurate placement of needle for caudal epidural injection with or without fluoroscopic guidance $(4,19-22)$. White et al (20) showed that incorrect needle placement occurred in approximately $25 \%$ of caudal epidural injections performed by an experienced anesthesiologist and orthopedic surgeon. Renfrew et al (21) showed that caudal epidural steroid injections performed by radiologists were incorrectly placed $38 \%$ of the time in experienced hands without to $S_{1}$ in $70 \%$ of the patients, followed by $L_{5}$ nerve root filling in $12 \%$ of the patients. Ventral epidural filling was seen in $69 \%$ of the patients, in contrast to dorsal filling in $92 \%$ of the patients. Nerve root filling correlated with leg pain in only $43 \%$ of the patients. Intravenous placement of the needle was noted in $14 \%$ of the patients with positive flashback and aspiration in $50 \%$ of the patients.

Conclusions: Caudal epidural injections are ideally performed with fluoroscopic guidance as the gold standard for accurate needle placement. However, this does not assure either targeted delivery or accurate placement of the drug.

Key Words: Caudal epidural injection, fluoroscopy, chronic low back pain, filling patterns, blind technique

fluoroscopy. Maigne et al (22) reported that they were successful at placing a needle in the caudal epidural space on a first attempt $68 \%$ of the time, improving to $85.3 \%$ after two attempts. Manchikanti et al (4) demonstrated that inaccurate placement of the needle during caudal epidural procedures was evident in $20 \%$ of cases. Stitz and Sommer (19) concluded that caudal epidural injections are performed ideally with fluoroscopic guidance as the gold standard for accurate drug placement. They showed that successful injection placement on the first attempt occurred in $74.1 \%$ of the patients. However, the results improved when anatomic landmarks were identified easily and no air was palpable subcutaneously over the sacrum when injected through the needle. Thus, they concluded that the combination of these two signs predicted a successful injection in $91.3 \%$ of the patients in a study of 54 consecutive patients. Other issues related to caudal epidural injections are intravascular injection and epidural filling pattern with targeted delivery of medication. Manchikanti et al (4) 
described highly variable filling patterns with the majority of the patients showing either inadequate filling or suboptimal filling in spite of injection of as high as $15 \mathrm{~mL}$ of contrast. Thus, epidural filling patterns will have significant effect on the targeted delivery of medication, as well as subsequent outcomes.

This prospective observational study was undertaken to establish the accuracy of blind versus fluoroscopically guided caudal epidural injections, to evaluate intravascular placement, to evaluate epidural and nerve root filling patterns, and correlate the filling patterns with pain patterns.

\section{Methods}

This prospective evaluation of caudal epidural injections under fluoroscopy was undertaken in an interventional pain management practice, a specialty referral center, in a private practice setting. The study protocol met the criteria of the Institutional Review Board. Inclusion criteria were consecutive patients undergoing caudal epidural injection. Exclusion criteria included pregnant or lactating women, patients with history of adverse reaction to local anesthetic, steroid, or contrast, patients unable to understand the informed consent or patients unable to be positioned in the prone position to perform the procedure.

The evaluation included demographic data of age, gender, weight, height, history of previous surgery, distribution of pain, and MRI or CT findings.

\section{Procedure}

A single technique by a single operator was utilized in all cases, which included sterile preparation, local anesthetic infiltration of the skin, and introduction of a \#20 Tuohy needle in all cases with the patient in prone position. The sacral hiatus was identified by palpation of the two sacral cornua and the interposed hiatal depression. Local anesthetic infiltration was carried out with a \#25 gauge $1 / 2$ " needle infiltrating $1 \%$ lidocaine, not to exceed $1 \mathrm{~mL}$. The Tuohy needle was directed into the sacral hiatus at an approximately $45^{\circ}$ angle with the bevel facing posteriorly. The needle was advanced, and directed to cannulate the sacral canal. When needle placement was believed to be correct, aspiration was performed to exclude venous or dural puncture. Following this, approximately 3 to $5 \mathrm{~mL}$ of air into the sacral canal was injected while palpating over the sacrum for subcutaneous flow.
Following this, $3 \mathrm{~mL}$ of Omnipaque 240 was injected once it was felt that the needle was in an appropriate position. Following this, the needle position and pattern of distribution of contrast were observed under fluoroscopy. If the needle was confirmed to be in the epidural space, additional Omnipaque, to bring the total to $10 \mathrm{~mL}$, was injected into the epidural space. Based on the filling pattern, the bevel of the needle was rotated, if necessary, to the side of the pain. If the needle was incorrectly placed, repositioning was carried out, and additional contrast was added to ensure uniform volume of contrast in all cases, i.e., $10 \mathrm{~mL}$.

The needle position and dispersion of contrast into the epidural space and nerve root filling was observed in posteroanterior and lateral views. Data was collected on the following aspects: number of attempts, C-arm time in seconds, positive flashback or aspiration, intravenous or intraarticular contrast filling, epidural filling in posteroanterior and lateral view, and finally, correlation of filling with pain. Data was also recorded with regards to pain during the injection, immediate pain relief, and complications. Pain relief was graded as none $(0 \%)$, poor ( $1 \%$ to $25 \%)$, fair $(26 \%$ to $50 \%)$, good $(51 \%$ to $74 \%)$, excellent $(>75 \%)$, and complete pain relief $(100 \%)$. Evaluation of complications included bleeding, swelling, pain, fever, muscle spasms, soreness at injection site, numbness, weakness, dizziness, nausea or vomiting, voiding difficulty, and other complications as reported by the patients.

\section{RESULTS}

\section{Patient Characteristics}

Demographic characteristics are illustrated in Table 1 with age, gender, weight, height, and previous surgery. $\mathrm{Pa}-$ tients were predominately female $(62 \%)$ with a mean age of $51.5 \pm 13.9$ years, mean weight of $180 \pm 49.6$ lbs. and a mean height of $66 \pm 4.1$ inches. Thirtyfive percent of the patients have had previous surgery.

Table 2 describes the pain distribution with $93 \%$ of the patients reporting bilateral low back pain compared to $62 \%$ of the patients reporting bilateral lower extremity pain.

\section{Table 1. Demographic characteristics}

\begin{tabular}{|l|l|c|}
\hline \multirow{2}{*}{ Age in years } & Range & $28-94$ \\
\cline { 2 - 3 } & Mean \pm SD & $51.5 \pm 13.9$ \\
\hline \multirow{2}{*}{ Gender } & Male & $38 \%(38)$ \\
\cline { 2 - 3 } & Female & $62 \%(62)$ \\
\hline Weight in lbs. & Mean \pm SD & $180 \pm 49.6$ \\
\hline Height in inches & Mean \pm SD & $66 \pm 4.1$ \\
\hline History of previous surgery & & $35 \%(35)$ \\
\hline
\end{tabular}

Table 2. Distribution characteristics of pain

\begin{tabular}{|l|c|c|}
\hline & Low Back Pain & Lower Extremity \\
\hline Right & $2 \%(2)$ & $13 \%(13)$ \\
\hline Left & $5 \%(5)$ & $25 \%(25)$ \\
\hline Bilateral & $93 \%(93)$ & $62 \%(62)$ \\
\hline
\end{tabular}

Table 3. Structural abnormalities as described by radiologist*

\begin{tabular}{|l|c|}
\hline Disc degeneration & $41 \%$ \\
\hline Facet arthropathy & $25 \%$ \\
\hline Spinal stenosis & $19 \%$ \\
\hline Disc bulging & $45 \%$ \\
\hline Disc Protrusion & $17 \%$ \\
\hline Disc herniation & $13 \%$ \\
\hline Epidural fibrosis & $34 \%$ \\
\hline No abnormalities & $15 \%$ \\
\hline
\end{tabular}

*Totals may not correlate, as some patients presented with more than one abnormality 


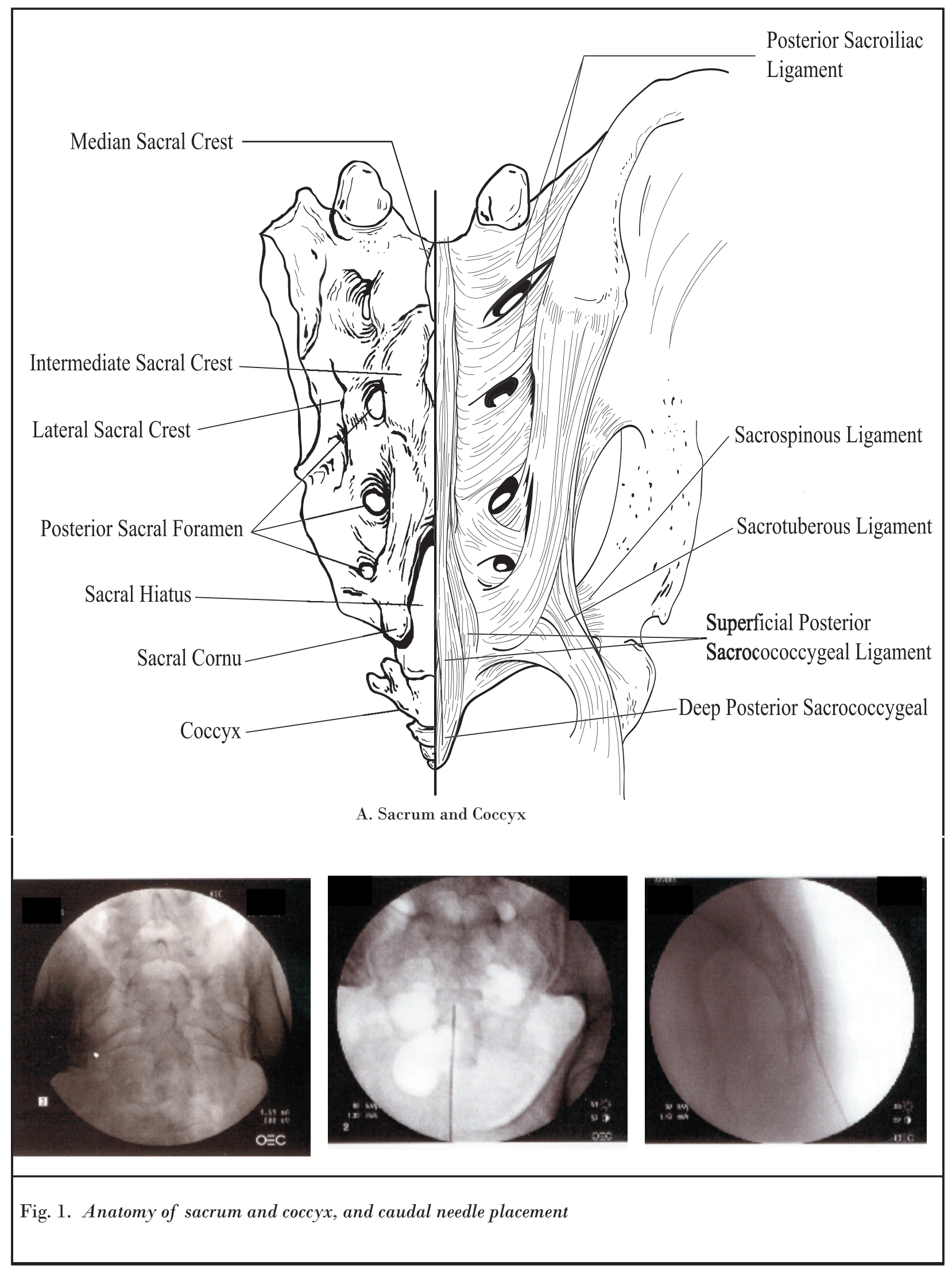

Pain Physician Vol. 7, No. 1, 2004 


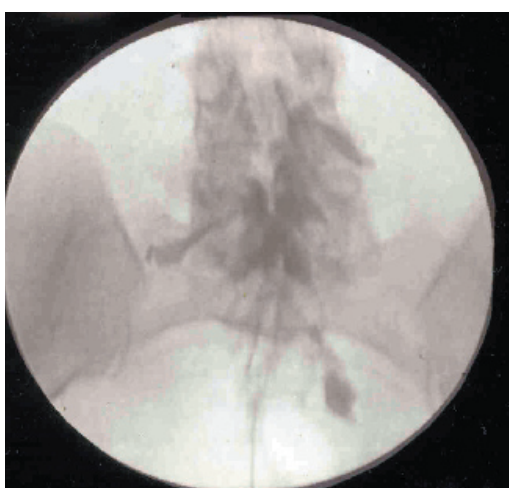

A. Normal epidural filling in posterior- anterior view

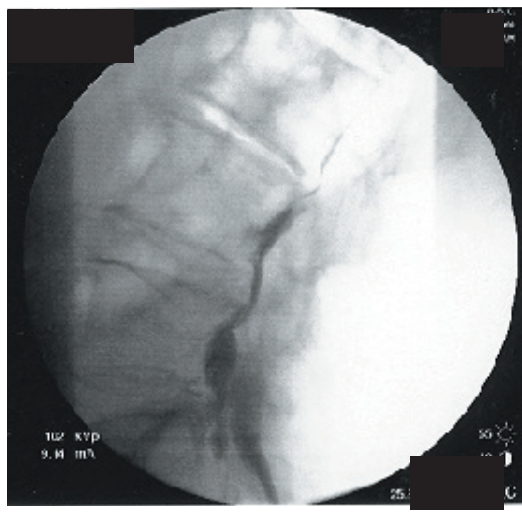

C. Ventral filling on lateral view

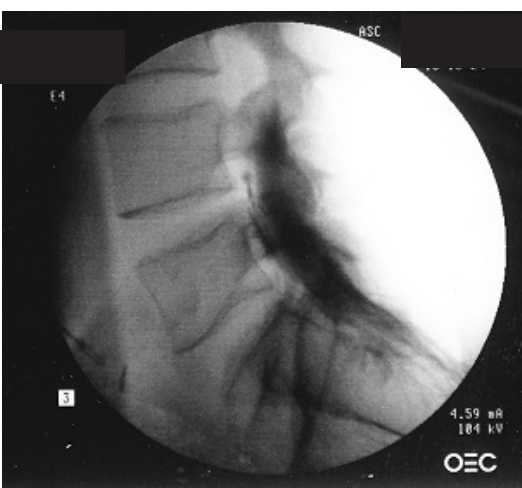

B. Dorsal filling on lateral view

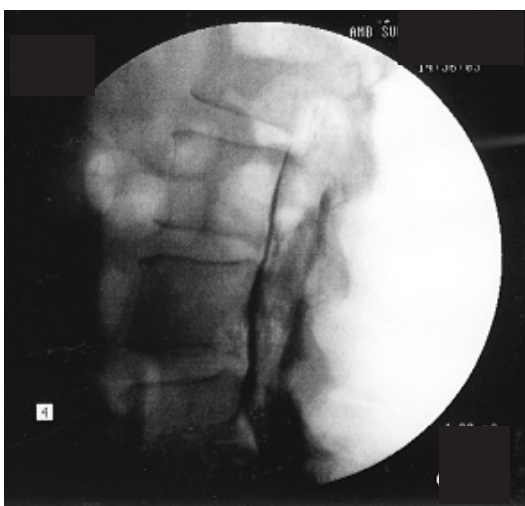

D. Dorsal and ventral filling on lateral view

Fig. 2. Typical filling patterns

Table 4. Needle placement characteristics

\begin{tabular}{|c|c|c|c|c|c|c|c|}
\hline \multirow{2}{*}{} & \multicolumn{3}{|c|}{ Number of attempts } & \multicolumn{5}{c|}{ Location of needle } \\
\cline { 2 - 9 } & 1 & 2 & $\geq 3$ & Epidural & Intravascular & Extra-epidural & Total misplacement \\
\hline Number of patients & 77 & 15 & 8 & 77 & 14 & 9 & 23 \\
\hline
\end{tabular}

Table 5. Contrast flow patterns of epidural space and nerve root filling

\begin{tabular}{|l|c|c|c|c|c|}
\hline \multirow{2}{*}{ Filling Level(s) } & \multicolumn{2}{|c|}{ Epidural Filling } & \multicolumn{3}{|c|}{ Nerve Root Filling } \\
\cline { 2 - 6 } & Dorsal & Ventral & Right & Left & Bilateral \\
\hline S1 & $23 \%$ & $41 \%$ & $16 \%$ & $7 \%$ & $36 \%$ \\
\hline L5 & $48 \%$ & $16 \%$ & $4 \%$ & $1 \%$ & $1 \%$ \\
\hline L4 & $12 \%$ & $8 \%$ & $2 \%$ & $0 \%$ & $0 \%$ \\
\hline L3 or above & $9 \%$ & $4 \%$ & $0 \%$ & $30 \%$ & \\
\hline None & $8 \%$ & $31 \%$ & \multicolumn{3}{|c|}{} \\
\hline
\end{tabular}

Table 6. Correlation of lower extremity pain and nerve root filling

\begin{tabular}{|l|c|c|c|c|}
\hline Filling & Right & Left & Bilateral & Total \\
\hline Yes & $\mathbf{9 ( 6 9 \% )}$ & $13(52 \%)$ & $\mathbf{2 1}(34 \%)$ & $43 \%$ \\
\hline No & $4(31 \%)$ & $12(48 \%)$ & $41(66 \%)$ & $57 \%$ \\
\hline Total & 13 & 25 & 62 & 100 \\
\hline
\end{tabular}


Table 7. Pain during the injection*

\begin{tabular}{|l|l|}
\hline Back pain & $43 \%(43)$ \\
\hline Leg pain or radicular pain & $22 \%(22)$ \\
\hline No pain & $43 \%(43)$ \\
\hline
\end{tabular}

* Some patients experienced both back and leg pain. Thus, totals may not correlate

Table 8. Complications*

\begin{tabular}{|l|c|}
\hline No complications & $76 \%(76)$ \\
\hline Soreness at injection site & $18 \%(18)$ \\
\hline Increased pain & $5 \%(5)$ \\
\hline Muscle spasms & $4 \%(4)$ \\
\hline Swelling & $4 \%(4)$ \\
\hline Headache & $3 \%(3)$ \\
\hline Minor bleeding & $2 \%(2)$ \\
\hline Dizziness & $1 \%(1)$ \\
\hline Nausea/Vomiting & $1 \%(1)$ \\
\hline Fever & $1 \%(1)$ \\
\hline Numbness & $1 \%(1)$ \\
\hline Voiding difficulty & $1 \%(1)$ \\
\hline Vasovagal reaction & $0 \%(0)$ \\
\hline Motor weakness & $0 \%(0)$ \\
\hline Insomnia & $0 \%(0)$ \\
\hline
\end{tabular}

* Some patients experienced more than one complication. Thus, totals may not correlate.

Structural abnormalities as identified by a radiologist, either on computerized tomography (CT) or magnetic resonance imaging (MRI) were evaluated (Table 3). Sixty-two patients had MRI results available, 17 patients had CT results available, whereas, $21 \%$ of the patients had both MRI and CT findings available.

\section{Procedural Characteristics}

Average C-arm time was $8.3 \pm 4.95$ seconds. The needle was found to be intravascular in $14 \%$ of the patients. However, no flashback and negative aspiration was noted in $7 \%$, or $50 \%$, of those patients with intravascular placement of the needle. Table 4 illustrates needle placement characteristics. Successful cannulation required one attempt in $77 \%$ of the patients, 2 attempts in $15 \%$, and 3 or more attempts in $8 \%$. The epidural needle was appropriately placed in $77 \%$ of the patients without fluoroscopic visualization and confirmed following the fluoroscopic visualization. Inaccurate placement was found in $23 \%$ of the patients. Intravascular placement was seen in $14 \%$, whereas, extra-epidural placement was seen in $9 \%$ of the patients with total misplacements of $23 \%$.

\section{Contrast Flow Patterns}

Figure 1 illustrates anatomical considerations. Figure 2 illustrates defined epidural and nerve root fillings. Any filling noted within one-third of the spinal canal close to the ventral surface was considered as ventral filling, whereas, filling to less than one third of the ventral area of the spinal canal was considered as dorsal filling. Figures 3-13 illustrate various filling patterns of epidural space and nerve roots.

Table 5 illustrates epidural and nerve root filling patterns as observed. Approximately two-thirds of the patients (69\%) showed ventral filling, whereas, most of the patients $(92 \%)$ showed dorsal filling. Nerve root fillings were also highly variable with S1 nerve root filling seen in 70\% of the patients.

Nerve root filling was correlated with lower extremity pain as shown in Table 6 . Nerve root filling correlated with leg pain pattern in $43 \%$ of patients only.

Pain Reproduction and Pain Relief

Reproduction of pain was seen in the low back in $43 \%$ of the patients and in lower extremity(s) in $22 \%$ of the patients during the procedure (Table 7). Eight percent of the patients experienced both back and lower extremity pain. Pain relief was seen in all the patients with $90 \%$ of the patients reporting $50 \%$ or greater relief immediately following the injection.

\section{Complications}

Complications were evaluated during the procedure immediately in the postoperative period as well as within 24 to 72 hours in the postoperative period. While soreness at injection site was the most common complication (18\%), no complications were described in $76 \%$ of the patients. Soreness varied significantly with number of attempts. It was seen in $13 \%$ of the patients with one attempt, in $27 \%$ of the patients with two attempts and in $50 \%$ of the patients with three or more attempts.

\section{DISCUSSION}

This prospective evaluation showed successful epidural placement of the needle in $77 \%$ of the patients without fluoroscopy. This study also showed misplacement of the needle in $23 \%$ of the 

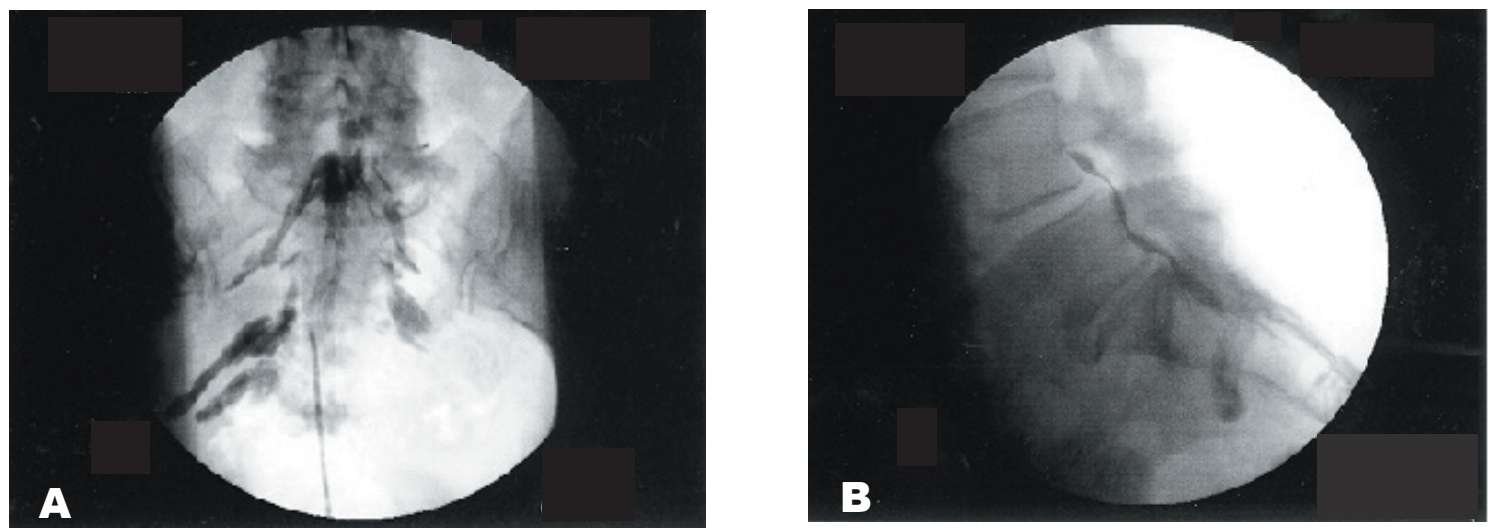

Fig: 3 Epidural filling pattern with nerve roots and ventral filling. Ventral filling on lateral view extends beyond the flow seen on PA View.
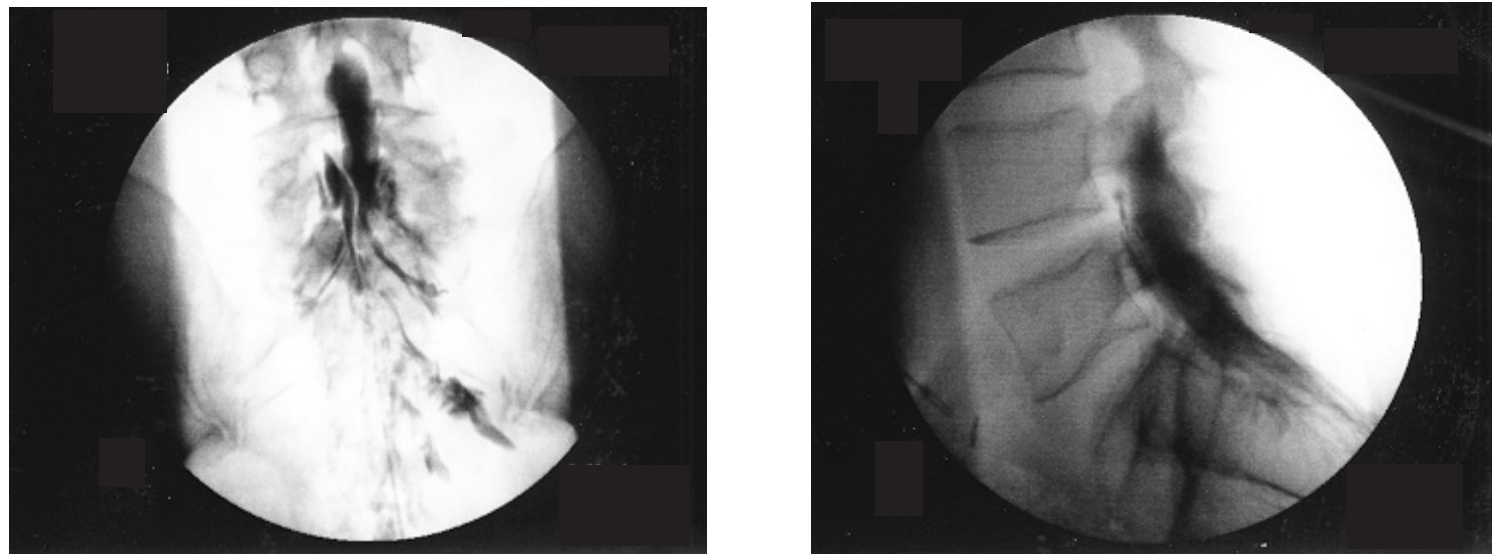

Fig. 4. Bilateral filling noted on PA view, with dorsal filling on lateral view
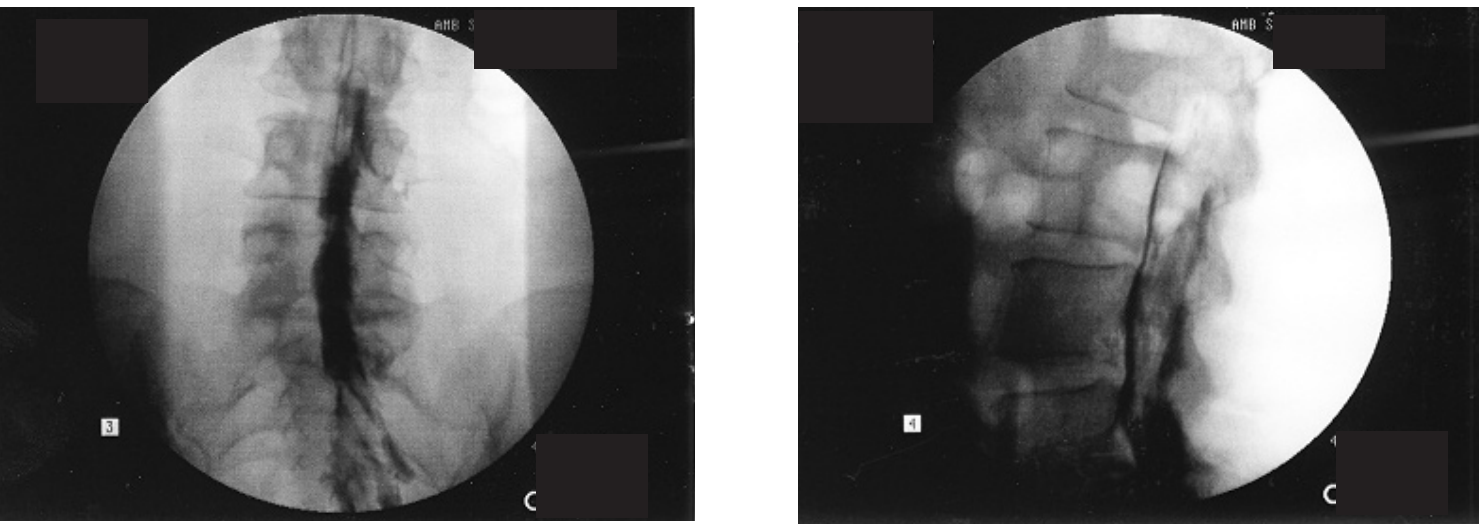

Fig. 5. Unilateral epidural filling on PA view with ventral and dorsal filling in a lateral view 

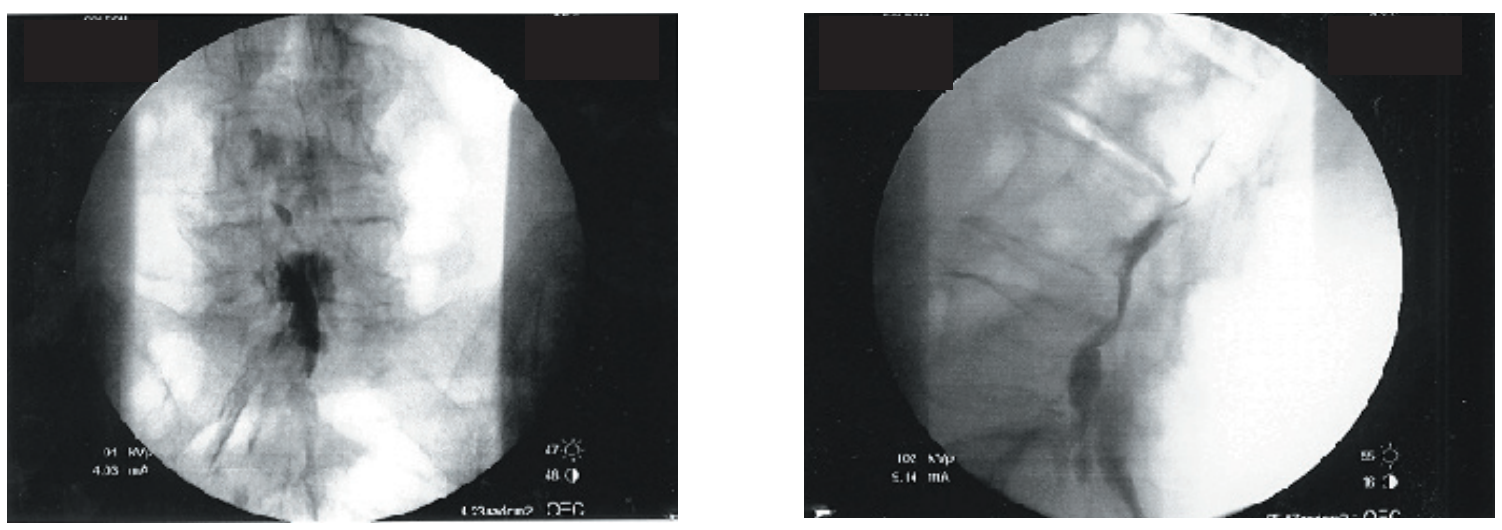

Fig. 6. Poor epidural filling on PA view with ventral filling on lateral view
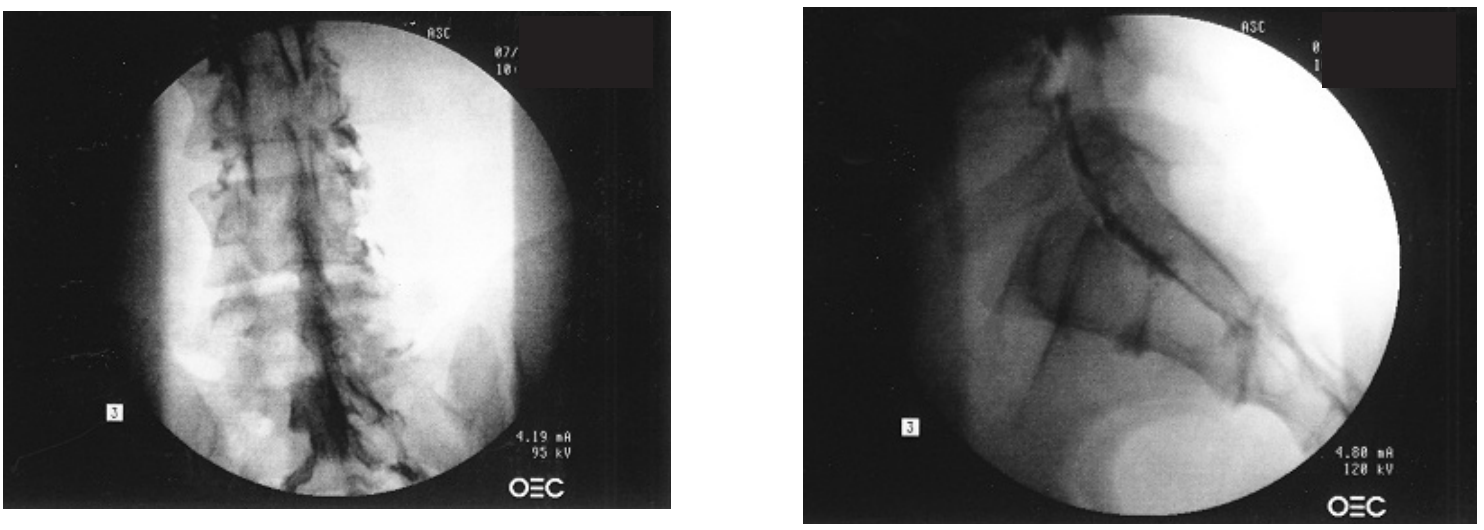

Fig. 7. Extensive epidural filling to LI level on PA view, with corresponding extensive filling on lateral view.
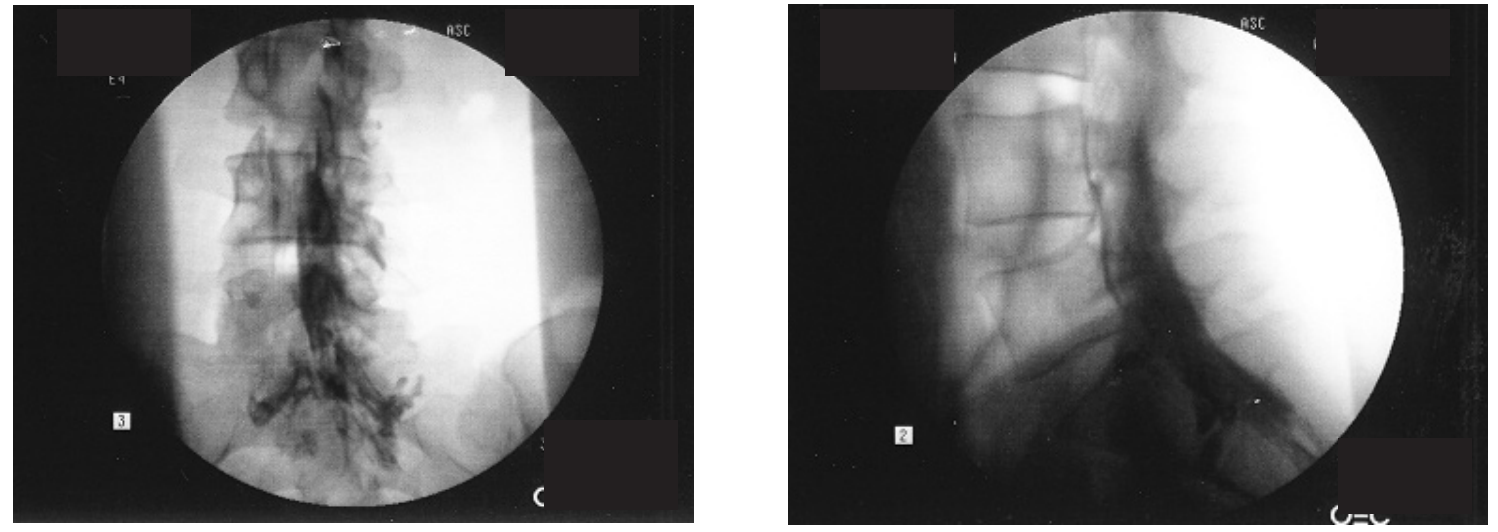

Fig. 8. Predominantly unilateral filling pattern on PA view, with ventral and dorsal filling on lateral view 

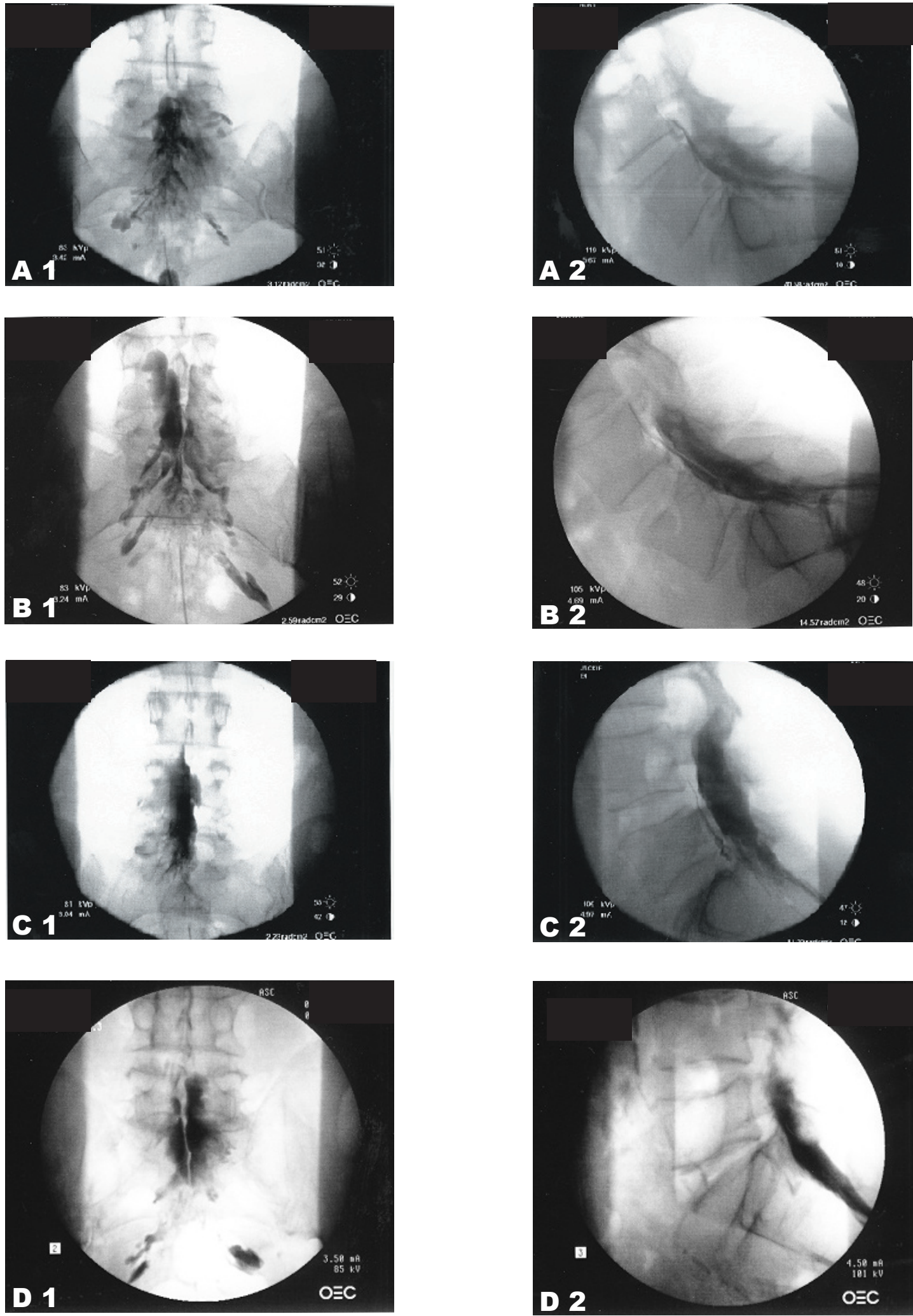

Fig. 9. Multiple epidural filling patterns on PA and lateral view 

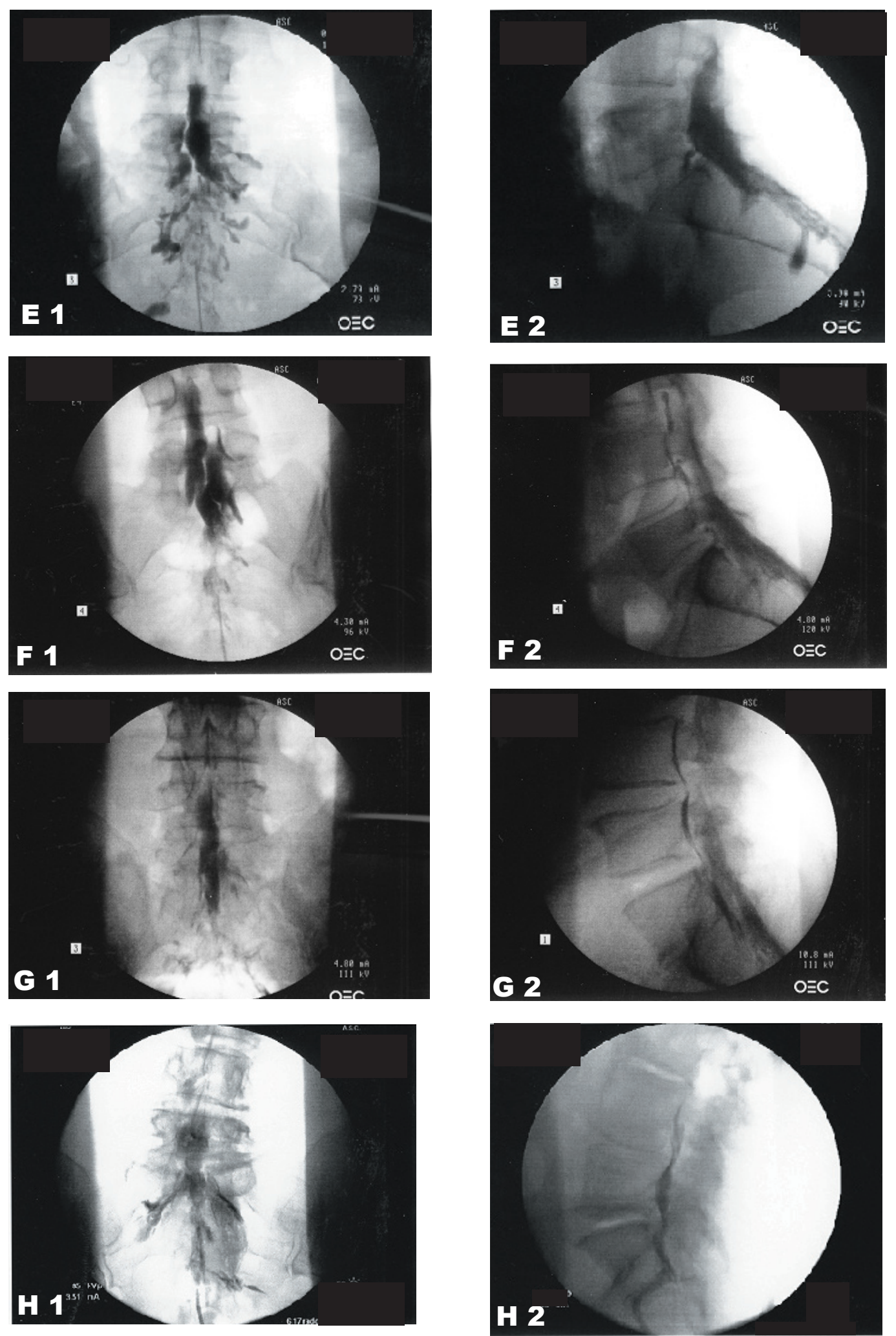

Fig. 10. Multiple filling patterns (Continued) 

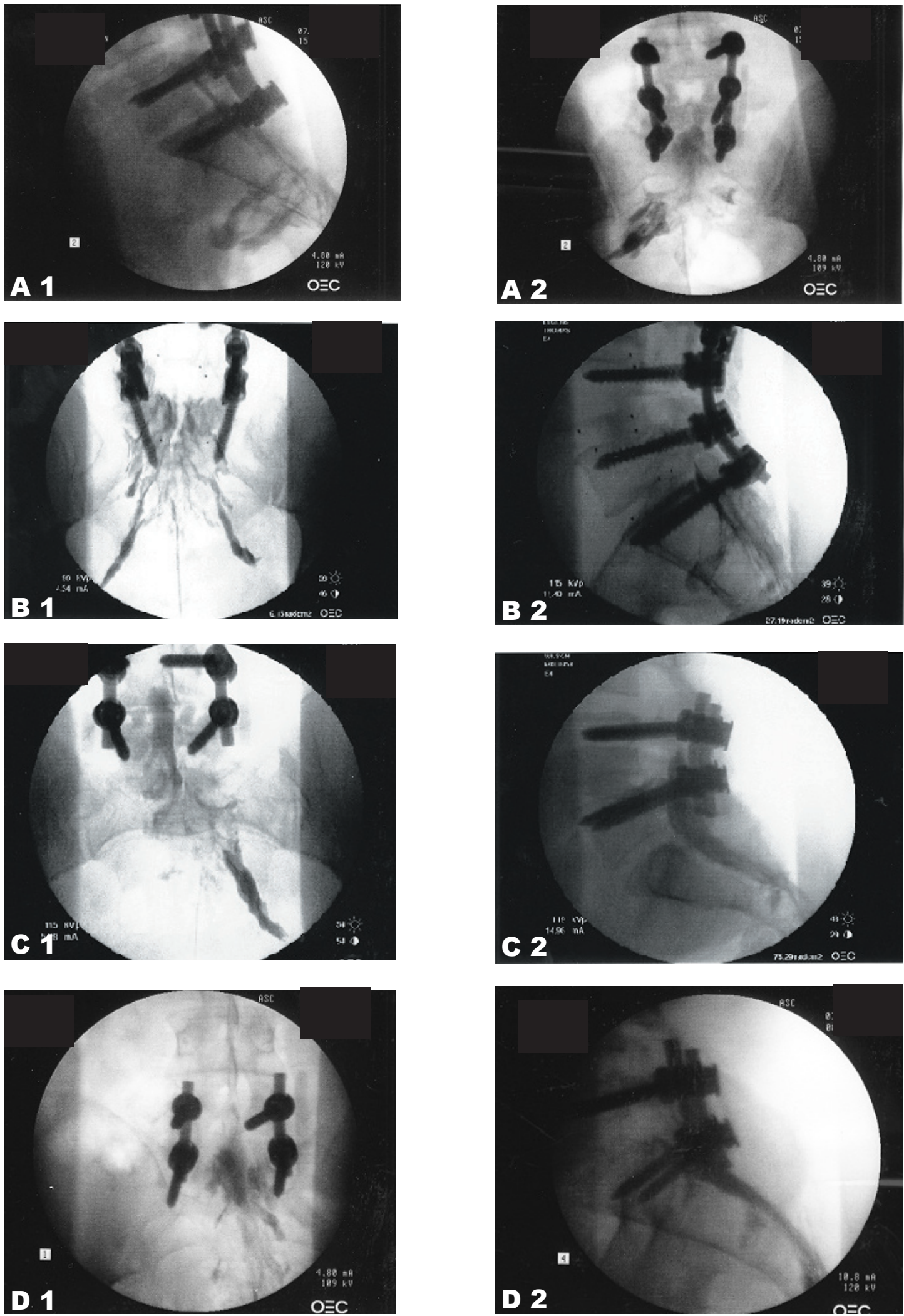

Fig. 11. Epidural filling patterns on $P A$ and lateral views in post surgical patients 
patients with $14 \%$ intravascular and $9 \%$ extra-epidural. Further, this evaluation showed dorsal epidural filling pattern in $92 \%$ of the patients in contrast to ventral epidural filling pattern in only $69 \%$ of the patients. Nerve root filling was also seen in $30 \%$ of the patients. Correlation of lower extremity pain in nerve root filling was noted in $43 \%$ of the patients.

The reasons for performing an epidural injection under fluoroscopic guidance may include accurate placement of the needle with ease, consequently potential accurate placement of the injectate, resulting in proper outcomes. However, the reasons for performing an epidural injection without fluoroscopy guidance may include the added cost of the fluoroscopy, inconvenient scheduling, non-availability of the equipment, facility location, ionizing radiation, allergy to contrast agents, and pregnancy. Thus, it is mandatory for interventional pain physicians to understand the pitfalls of both fluoroscopy and performing the procedure without fluoroscopy, and to ensure that the procedure is performed as accurately and safely as possible. Previous studies have shown that incorrect needle placement during epidural injection occurs with relative frequency when performed without the use of fluoroscopic guidance $(4,19-23)$. With a caudal technique, the most common incorrect needle placement appears to be in a significant proportion of patients either with subfacial placement or unrecognized intravascular placement. Multiple investigators over the years $(4,19-25)$ have shown incorrect placement without fluoroscopy to range from a low of $8 \%$ to a high of $38 \%$ in experienced hands. They also showed unrecognized intravascular placement to range from $3.7 \%$ to $9 \%$. The average inaccurate placement was $36 \%$, whereas, intravascular placement was $6.5 \%$ of the individuals receiving caudal epidural injections.

Renfrew et al (21) prospectively evaluated 316 caudal epidural steroid injections given by staff radiologists and residents over a period of one year. They showed that the success rate of epidural steroid injections was variable with physician experience. The correct non-fluoroscopically directed placement of the needle was seen only in $48 \%$ of the patients when physicians were judged who had given fewer than 10 epidural steroid injections, whereas, when physicians had performed between 10 and 50 such procedures, success rate was $54 \%$, in contrast to staff physicians with a success rate of $62 \%$. They reported that, even when the sacral hiatus was easily palpated and the staff physician was confident of the position of the needle being in the epidural space, fluoroscopy revealed incorrect placement in $14 \%$ of the patients. In addition, they showed that when the needle was positioned within the sacral canal and no blood was evident on Valsalva maneuver or aspiration, the injection was venous in $9 \%$ of the cases. White et al (20) showed incorrect placement in $25 \%$ of the patients with intravascular placement in $6.4 \%$ of the patients. Manchikanti et al (4) showed that the needle was successfully placed in $80 \%$ of the patients without fluoroscopy with $7 \%$ with intravascular placement and 13\% with extra-epidural placement. Stitz and Sommer (19) showed appropriate placement in $74 \%$ of the patients without fluoroscopy with $3.75 \%$ intravascular placement. Maigne et al (22) showed that they were successful at placing a needle in the caudal epidural space on a first attempt $68 \%$ of the time, improving to $85 \%$ after two attempts. Price et al (24) reported accurate placement only in $64 \%$ of the patients. In contrast, Eastwood and Buchan (25) reported accurate placement in $92 \%$ utilizing a "whoosh test." Whoosh test involves injection of air into the caudal epidural space and simultaneous auscultation over the thoracolumbar spine to aid in correct needle placement.

The current results, though similar to some of the previous reports (19-24), and higher than one report (25), overall show a higher proportion of correct needle placement on average (23\% vs $36 \%)$. Unrecognized vascular placement was also variable with the previous studies, however, overall it was higher than the average incidence of intravascular placement reported thus far.

One of the major concerns about lumbar and caudal epidural steroids is that their true efficacy might not be evident in clinical trials because the injectate fails to reach the desired target $(7,8$, $13,20,26,27)$. It has been postulated that even a well-performed caudal epidural injection might fail to afford appropriate relief because the drug never reaches the required target in appropriate concentrations. Thus, the objective of an epidural steroid injection is to deliver corticoste- roid close to the site of pathology, presumably onto an inflamed nerve root. This is based on the premise that the corticosteroid delivered into the epidural space attends higher local concentrations over an inflamed nerve root and will be more effective than a steroid administered either orally or by intramuscular injection. Target site concentrations of steroids depend upon multiple injection variables, though mainly it is the route of epidural administration. Caudal epidural injections, similar to interlaminar epidural injections, are affected by the presence or absence of epidural ligaments or scarring, which may prevent migration of the posterior administered injectate to the anterior epidural space. In normal volunteers it was shown that the transforaminal approach showed good ventral flow, whereas, the interlaminar method showed predominantly dorsal flow, which was far removed from the usual site of inflammation (26). Saal and Saal (27) described various factors leading to the failure of epidural corticosteroid injections. These included: insurmountable pathology; inadequate delivery of corticosteroid to the target site; and non-injection factors, including inappropriate post block activity, misinterpretation of pain generator, and unmasking phenomenon (13). Thus, it appears that the major factor is the technical one of the delivery of medication to the epidural space. Thus, we have evaluated nerve root filling, as well as the ventral filling in this study. Appropriate nerve root filling was noted only in $43 \%$ of the patients, whereas, ventral filling of the epidural space was noted in $69 \%$ of the patients. Thus, it appears that in spite of $10 \mathrm{~mL}$ of volume under fluoroscopic visualization, injectate may not reach the target site in a significant proportion of patients. Even then, significant pain relief was noted in the immediate postoperative period. This study also showed in $43 \%$ of the patients reproduction of back pain, and in $22 \%$ reproduction of leg pain.

There were no major complications. All the complications were minor. These ranged from minor bleeding, fever, dizziness, nausea/vomiting in $1 \%$ of the patients to soreness at injection site reported in $18 \%$ of the patients. Soreness at injection site significantly increased with number of attempts ( $13 \%$ with one attempt vs $35 \%$ with two or more attempts). Seventy-six percent of the patients reported no complications. 


\section{CONCLUSION}

This prospective evaluation showed successful epidural placement of the needle in $77 \%$ of the patients without fluoroscopy. This study also showed misplacement of the needle in $23 \%$ of the patients with $14 \%$ intravascular and $9 \%$ extra-epidural. In $50 \%$ of the patients with intravascular placement, flashback, and aspiration were negative. Ventral epidural filling was noted in $69 \%$ of the patients with appropriate nerve root filling noted in only $43 \%$ of the patients. Thus, it appears that in spite of fluoroscopic administration of caudal epidural injections, target delivery may not be possible in the majority of the patients. Soreness at injection site significantly increased with number of attempts ( $13 \%$ with one attempt vs $35 \%$ with two or more attempts).

\section{ACKNOWLEDGMENTS}

The authors wish to thank Tonie Hatton, transcriptionist; Sheila Jackson, RN, Doris E. Brandon, CST, Sue R. Wilson, ORT, and Victoria L. Hicks, ORT; for their assistance in preparation of this manuscript.

\section{REFERENCES}

1. Sicard MA. Les injections medicamenteuse extradurales par voie saracoccygiene. Comptes Renues des Seances de la Societe de Biologie et de ses Filliales (Paris) 1901;53:452-453.

2. Cathelin MF. Mode d'action de la cocaine injecte daus l'escape epidural par le procede du canal sacre. Comptes Rendues des Seances de la Societe de Biologie et de ses Filliales (Paris) 1901; 43:487.

3. Pasquier MM, Leri D. Injection intra-et extradurales de cocaine a dose minime daus le traitments dela sciatique. Bull Gen Ther 1901;142:196.

4. Manchikanti L, Bakhit CE, Pampati V. Role of epidurography in caudal neuroplasty. Pain Digest 1998; 8:277-281.

5. Singh V, Manchikanti L. Role of caudal epidural injections in the management of chronic low back pain. Pain Physician 2002; 5:133-148.

6. Boswell MV, Hansen HC, Trescot AM et al. Epidural steroids in the management of chronic spinal pain and radiculopathy. Pain Physician 2003; 6:319-334.

7. Manchikanti L, Staats P, Singh V et al. Evidence-based practice guidelines for interventional techniques in the management of chronic spinal pain. Pain Physician 2003; 6:3-80.

\section{Author Affiliation:}

Laxmaiah Manchikanti, MD

Medical Director

Pain Management Center of

Paducah

2831 Lone Oak Road

Paducah, Kentucky 42003

E-maildrm@apex.net.

\section{Kim A. Cash, RT}

Radiological Technologist

Pain Management Center of

Paducah

2831 Lone Oak Road

Paducah, Kentucky 42003

\section{Vidyasagar Pampati, MSc}

Biostatistician

Pain Management Center of

Paducah

2831 Lone Oak Road

Paducah, Kentucky 42003

E-mail sagar@thepainmd.com

Carla D. McManus, RN, BSN

Clinical Coordinator

Pain Management Center of

Paducah

2831 Lone Oak Road

Paducah, Kentucky 42003

Kim S. Damron, RN

Clinical Coordinator

Pain Management Center of

Paducah

2831 Lone Oak Road

Paducah, Kentucky 42003

8. Bogduk N, Christophidis N, Cherry D et al. Epidural use of steroids in the management of back pain. Report of working party on epidural use of steroids in the management of back pain. National Health and Medical Research Council. Canberra, Commonwealth of Australia, 1994, pp 1-76.

9. Manchikanti L, Pakanati RR, Pampati V. Comparison of three routes of epidural steroid injections in low back pain. Pain Digest 1999; 9:277-285.

10. Manchikanti L, Pampati V, Rivera J et al. Caudal epidural injections with Sarapin or steroids in chronic low back pain. Pain Physician 2001; 4:322-335.

11. Manchikanti L., Singh V, Rivera J et al. Effectiveness of caudal epidural injections in discogram positive and negative chronic low back pain. Pain Physician 2002; 5: 18-29.

12. Botwin KP, Gruber RD, Bouchlas CG et al.
Complications of fluoroscopically guided caudal epidural injections. Am J Phys Med Rehabil 2001; 80:416-424.

13. Manchikanti L. Transforaminal lumbar epidural steroid injections. Pain Physician 2000; 3:374-398.

14. Helm S, Jasper JF, Racz GB. Complications of transforaminal epidural injections. Pain Physician 2003; 6:389-390.

15. Houten JK, Errico TJ. Paraplegia after lumbosacral nerve root block: Report of three cases. The Spine Journal 2002; 2:70-75.

16. Brouwers PJ, Kottink EJ, Simon MA et al. A cervical anterior spinal artery syndrome after diagnostic blockade of the right C6nerve root. Pain 2001; 91:397-399.

17. Nash TP, Brouwers PJ, Ella JB et al. Comment on A cervical anterior spinal artery syndrome after diagnostic blockade of the right C6-nerve root. Pain 2001; 91:217218.

18. Stohr M, Mayer K. Nerve-root damage from local injections. Dtsch Med Wochenschr 1976; 101:1218-1220.

19. Stitz MY, Sommer HM. Accuracy of blind versus fluoroscopically guided caudal epidural injection. Spine 1999; 24:13711376.

20. White AH, Derby R, Wynne G. Epidural injections for the treatment of low back pain. Spine 1980; 5:78-86.

21. Renfrew DL, Moore TE, Kathol $\mathrm{MH}$ et al. Correct placement of epidural steroid injections: Fluoroscopic guidance and contrast administration. Am J Neuroradiology 1991; 12:1003-1007.

22. Maigne JY, Gourjonj A, Maigne R. Taux de Reussite des Trois Techniques d'Injection Epidurale: Etude de l'Etalement d'un Contraste Radio-opaque. Revue du Rhumatisme 1990; 57:575-578.

23. Saha AK, Shah VM, Vakhariya V et al. To do or not to do under fluoroscopy, that is the question: An analysis of sacroiliac joint and caudal epidural injections in a pain center. Am J Anesthesiol 1999; 26:269-271.

24. Price CM, Rogers PD, Prosser AS et al. Comparison of the caudal and lumbar approaches to the epidural space. Ann Rheum Dis 2000; 59:879-882.

25. Eastwood D, Williams C, Buchan I. Caudal epidurals: The whoosh test. Anaesthesia 1998; 53:305-307.

26. Andrade A, Eckman E. The distribution of radiologic contrast media by lumbar translaminar and selective neural canals in normal human volunteers. Proceedings of the Annual Meeting of the International Spinal Injection Society, Keystone, CO, January 1992.

27. Saal JA, Saal JS. Comprehensive cervical and lumbar intra-spinal injection course. Stanford University School of Medicine, Stanford, California, July 11-12, 1998. 